\title{
Para uma leitura semiótica das teorias de framing: reinterpretando o enquadramento com base na categoria peirceana de terceiridade
}

Anabela Gradim

Resumo: Explorar a peculiaridade semiótica das teorias de framing, questionando simultaneamente novos enquadramentos para a história da semiótica e do seu campo é o propósito deste estudo. As pesquisas sobre framing, muito profícuas na análise jornalística e na crítica mediática, têm uma origem multifacetada que o trabalho examina, procurando inserir uma nova linha nessa genealogia, particularmente descurada, e que tem a ver com o trabalho da semiótica como instrumento hermenêutico de criação de sentido. As categorias peirceanas são apresentadas como método que permite explicitar os mecanismos de enquadramento ou frames latentes nos seus produtores, no texto mediático, e na recepção pela audiência, perspectivando-se a terceiridade como elemento criador de regras ou habitus interpretativos, que identificaremos com o framing nas narrativas, e como paradigma integrador capaz de superar a fragmentação do campo e das suas origens.

Palavras-chave: semiótica; framing; Peirce.

Abstract: A semiotic reading of "framing theories": reinterpreting framing through the Peircean category of thirdness - This paper explores the semiotic character of framing theories, while suggesting new frameworks for the history of semiotics and its field. Frame studies, which are very fruitful in journalistic analysis and media criticism, have diverse sources. This work explores them, seeking to introduce a new strand to this genealogy, one that is particularly overlooked and relates to the work of semiotics as hermeneutical instrument for creating sense and meaning. Peirce's category system is then presented as a method for exposing the underlying mechanisms of framing, found in their producers, in media texts and in the audience. Thirdness is envisaged as an element that creates rules or interpretative habitus, which will be identified with framing in narratives, and as an integrating paradigm that is able to overcome the fragmentation of the field of frame studies and its origins.

Keywords: semiotics; framing; Peirce. 
Nos últimos anos, os estudos de framing aplicados à produção mediática (NORRIS et al., 2003; JOHNSON-CARTEE, 2004; BIRKLAND e LAWRENCE, 2009) e à comunicação política (LAKOFF et al., 2004; KAREN e FRAUKE SCHNELL, 2005) têm conhecido um desenvolvimento e diversidade notáveis. Quando falamos em enquadramento, a análise pode operar em três níveis (REESE et al., 2001): no processo de produção e reprodução de frames; na avaliação empírica, quantitativa e qualitativa, ligada a case studies particulares; ou centrando-se no estudo dos efeitos, da interação entre textos e audiências para a produção de sentido e narrativas comuns.

Já como método, os estudos de framing tanto podem socorrer-se da análise paradigmática de conteúdo, conduzida em profundidade sobre objetos bem definidos; como da análise comparativa e sintagmática: diferentes enquadramentos sobre objetos ou acontecimentos mediáticos, idênticos ou equiparáveis, fazem ressaltar a qualidade de constructo dos diversos níveis de sentido que lhe são atribuídos e por meio dos quais o evento será percebido²

Se esta diversidade do campo expressa vitalidade, é também índice das dificuldades que Entman (1993) caracterizou com a metáfora do "paradigma fracturado": não há nem uma univocidade terminológica nem metodológica que permita unificar o campo dos estudos de framing; mas, mesmo por sobre a dispersão do conceito, ele poderia constituirse como paradigma e método para os estudos em comunicação na opinião de Entman.

Frame ou enquadramento pode definir-se como o conjunto de pistas, visuais ou linguísticas e conceptuais, que enformam o contexto de um objecto ou acontecimento. Essas pistas de como o evento deve ser interpretado constituem o seu enquadramento propriamente dito, salientando certos aspectos deste e obscurecendo outros; e são susceptíveis a apresentar muitas formas, com alcances diversificados: podem referir-se a um objecto concreto, como tratar-se de meta construções simbólicas e culturais que servem de contexto a um conjunto de narrativas de alcance muito vasto.

Algumas definições influentes no campo dos estudos em comunicação e jornalismo incluem as de Todd Gitlin, que as considera resultado das rotinas produtivas dos jornalistas, como elementos produtores e dispensadores de ideologia, aparecendo aos olhos do público como mundividências naturalizadas, auto-evidentes e dificilmente questionáveis. Não um objecto prontamente identificável, mas o resultado de um processo, Gitlin (1980) caracteriza as frames como "princípios de seleção, ênfase e apresentação, compostas de pequenas teorias tácitas sobre o que existe, o que acontece, e o que tem importância".

1 Por exemplo, BIRKLAND, T. A.; LAWRENCE, R. G. "Media framing and policy change after Columbine". American Behavioral Scientist, 2009; GAMSON, W.; MODIGLIANI, A. "Media discourse and public opinion on nuclear power: A constructionist approach", American Journal of Sociology, vol. 95, nº1, 2010 [1989]; e ENTMAN, R. M. "Media framing biases and political power: Explaining slant in news of Campaign 2008". Journalism, 11(4), 389-408, 2010.

2 Exemplo clássico deste segundo tipo de estudos, empregando análise comparativa: ENTMAN, R. M. "Symposium framing U.S. coverage of international news: Contrasts in narratives of the KAL and Iran Air incidents". Journal of Communication, 41: 6-27, 1991. 
Inseparáveis das rotinas de produção jornalística, que tornam possível o ciclo de vida da notícia, presidem quer à recolha e produção da informação, quer à sua recepção por parte da audiência, constituindo-se como verdadeiros princípios de cognição invisíveis e omnipresentes.

Na mesma linha, Gaye Tuchman (1980) considera as frames no âmbito dos dispositivos de domesticação do imprevisto por parte das rotinas jornalísticas, convocando a metáfora da "janela" para veicular esta ideia: as notícias são como que "uma janela para o mundo", enquadrando aquilo que mostram, e relegando para o fora de campo tudo que a "janela" não deixa ver.

Da "janela" para os "óculos", Bourdieu (1997) com a sua metáfora afasta dos constrangimentos organizacionais e aproxima do agenciamento do sujeito as decisões de enquadramento: "os jornalistas têm óculos especiais a partir dos quais veem certas coisas e não outras; e veem de certa maneira as coisas que veem. Eles operam uma selecção e dramatização do que é selecionado"; ou seja, frames são "estruturas invisíveis que organizam o percebido, determinando o que se vê e o que não se vê".

Entman (1993), para quem o enquadramento é "a seleção de alguns aspectos de uma realidade percebida, tornando-os mais salientes num contexto comunicativo, de modo a promover uma definição particular do problema, uma interpretação causal, uma avaliação moral, e uma recomendação de tratamento", ao articular esses quatro aspectos, oferece uma das definições mais completas do conceito³; mas são Gamson (1989), e Bird e Dardenne (2009) que chamam a atenção para a especificidade narrativa das frames, e de como podem perdurar no tempo, constituindo-se como dispositivo trans-mediático e trans-narrativo.

Frames como grandes meta-narrativas transmediáticas são apresentadas por Gamson e Modigliani (1989) ao longo do seu estudo sobre meio século de discurso mediático relativo à energia nuclear. Aqui, o enquadramento é apresentado como um "pacote cultural" muito vasto composto por "metáforas, slogans, imagens visuais, apelos morais e outros dispositivos simbólicos", como ressonâncias culturais, histórias, mitos e crenças populares, que ajudam a fixar junto à opinião pública a interpretação dos factos prevalecente. No caso da energia nuclear, no espaço de 50 anos, Gamson e Modigliani (ibidem) detectam "pacotes interpretativos" coexistentes e concorrentes, que dão sentido ao tema, até chegarmos ao discurso contemporâneo. São eles, nos EUA, até aos anos 50, a frame da destruição massiva ligada ao trauma de Hiroxima; a frame concorrente do "progresso desenvolvimentista", que encara o nuclear como uma alternativa energética económica e democrática, popular até os anos 60; e, por fim, nos anos 70, a ascensão do discurso anti-nuclear, preocupado com os perigos da radiação e dos testes nucleares, e que é hoje a frame ou o pacote cultural interpretativo dominante nestas questões (ibidem, p. 15).

Não longe desse registro, Bird e Dardenne (2009) comparam os jornalistas a bardos, e as notícias às narrativas míticas. Não literalmente, é claro. O ponto é que as notícias,

3 Entre os quatro elementos necessários ao funcionamento da frame contam-se definirem os problemas; diagnosticarem causas; realizarem julgamentos morais; e sugerirem soluções (ibidem). 
não individualmente, mas se tomadas no seu conjunto, funcionam à maneira do mito tal como foi caracterizado nos anos 60 e 70 por Lévy-Strauss e Mircea Eliade: narrativas que "ajudam a manter o sentido de continuidade e ordem no mundo".

O grau de permanência e a profundidade a que ocorrem estes fenómenos de formação de molduras culturais interpretativas que se assemelham, no seu funcionamento, a construções míticas, explicam por que o mais difícil de mudar numa sociedade são os quadros mentais e culturais - mesmo quando à superfície parece ter-se operado a mudança - e também o poder de apelar aos mitos e traumas profundos da psique colectiva numa dada cultura como estratégia de comunicação e mobilização política, aspecto analisado com excepcional clareza por George Lakoff et al (2004) em Don't think of an elephant.

\section{Uma origem plural}

Essa variedade de definições contemporâneas que examinamos, assumindo especial importância no contexto da comunicação mediatizada pelos efeitos que produzem junto à opinião pública, tem a sua origem nas três linhas genealógicas fundadoras que podemos atribuir aos estudos de framing: Gregory Bateson com os estudos sobre o jogo e a esquizofrenia; Erving Goffman com os trabalhos sobre a interação estratégica, e Berger e Luckman com o interacionismo social.

Com efeito, Goffman atribui à leitura de Bateson as sugestões que o levaram a escrever Frame analysis - an essay on the organization of experience. Em Steps to an ecology of the mind, ao abordar a questão da esquizofrenia, Bateson (1972) sugere que a linguagem opera em três níveis: denotativo ou literal; metalinguístico, em que a própria mensagem é sujeito da linguagem; e metacomunicativo, em que o sujeito do discurso é a relação entre os enunciadores. Quando o sujeito perde a capacidade de se expressar e descodificar mensagens em nível metacomunicativo, perde a capacidade de discernir de que tipo uma mensagem é - se jogo, ameaça, fantasia, trabalho, entrevista... -, ou seja, de compreender o seu enquadramento (ibidem, p. 190). Estão lançadas as bases para a disfunção comunicacional que culmina na esquizofrenia quando, sujeito a situações repetidas de trauma (double bind) relativamente ao nível metacomunicativo, o indivíduo opta simplesmente por retirar-se da situação de comunicação, mudando-se para uma ordem metafórica da linguagem. Nesse quadro, qualquer intervenção terapêutica tem de situar-se no nível da manipulação das frames ${ }^{4}$, pois é a dificuldade em descodificar sinais de tipo metacomunicativo "que parece estar no centro de um síndrome que é característico de um grupo de esquizofrénicos" (ibidem, p. 199).

Erving Goffman (1993) centrará o seu trabalho no processo dialético de apresentação do sujeito em situações sociais, análise para a qual empregará preferencialmente metáforas

4 "A dependência da psicoterapia da manipulação de frames segue-se do facto de que essa terapia é uma tentativa de alterar os hábitos metacomunicativos do paciente. Antes da terapia, o paciente pensa e opera em termos de um certo conjunto de regras para a construção e compreensão de mensagens. Depois de uma terapia bem sucedida, opera em termos de um conjunto diferente de tais regras" (BATESON, 1972). 
da ordem da dramaturgia (máscara, teatro, palco, cena, representação), num cenário em que também é exigida uma interpretação dos elementos metacomunicativos em causa, ou seja, do enquadramento sempre volátil do jogo social da exposição do sujeito. Esse tema é expandido para quadros e situações sociais em Frame analysis (idem, 1974), em que o autor trabalha a organização da experiência, distinguindo entre frames primárias e secundárias; e entre frames naturais e sociais. "Frame é a palavra que uso para me referir àqueles elementos básicos [princípios de organização que governam os acontecimentos e contribuem para a definição de uma situação] que consigo identificar. Essa é a minha definição de frame. A minha frase 'análise de frames' é um slogan para me referir à avaliação, nestes termos, da organização da experiência" (ibidem).

O contributo de Berger e Luckman (1974) ocorre a propósito da sua ligação ao interacionismo simbólico em $A$ construção social da realidade. A tese principal da obra é de que a realidade é socialmente construída pelas interações entre pessoas e grupos. Quando essas interações perduram no tempo, acabam por institucionalizar-se, fixando-se em papéis sociais reconhecíveis pelos membros do grupo e geradores tanto de expectativas como de desempenhos. A realidade é socialmente construída e o consenso sobre o que essa realidade é produz-se pelas interações sociais dos sujeitos.

\section{Framing e semiótica}

A genealogia dos estudos de framing, perspectivada à luz semiótica, deixa ver muito claramente as afinidades entre os dois discursos e metodologias: o framing também se ocupa da criação e produção de sentido, em níveis micro e macrossociológicos. Os teóricos do enquadramento, sobretudo no campo dos estudos de media, empregam um foco bem determinado: que quadros mentais permitem ver o que vejo, regulam a construção do que o real é para o sujeito, e como são esses quadros mentais produzidos; ou seja, buscam pela origem das crenças do sujeito sobre o real, e dos hábitos interpretativos que reforçam essas crenças.

Ora é a criação de sentido o principal foco da semiótica, que aqui entendemos como o estudo sistemático de significantes, significados, e seus efeitos, o que corresponde diretamente à tese de Reese (2001) de que frames encontram-se e podem ser estudadas em três níveis: no processo de produção, no texto produzido, e nas audiências.

Se, quando falamos de framing, falamos essencialmente de significação, de como fazer sentido do real, é evidente que este trabalho é do domínio da semiótica. Daí considerarmos que tem a semiótica um papel a desempenhar nos estudos de framing, podendo ser entendida não só como linha genealógica desses estudos, mas mesmo como paradigma que permitisse reencontrar-Ihe, enfim, uma unidade epistemológica por sobre a diversidade das suas origens.

Uma ligação explícita do framing a essa filiação semiótica, e também à semiótica peirceana, é colocada por Stuart Hall num texto célebre: Encoding/ Decoding. 
Hall (2001) nota que um "evento em bruto" ${ }^{5}$ não pode ser transmitido por um media. No caso da televisão, "os eventos só podem ser significados no interior das formas aurais e visuais do discurso televisivo (...) um evento tem de se tornar uma história para poder ser um evento comunicativo". E isso sucede por meio da estrutura e das rotinas produtivas institucionalizadas no medium, que determinam "tópicos, tratamentos, agendas, acontecimentos, pessoal, imagens das audiências, 'definições da situação' a partir de outras fontes e outras formações discursivas no interior da estrutura sociocultural e política mais vasta de que são uma parte diferenciada" (ibidem). Não existindo coincidência entre os códigos da fonte e do emissor, é, no entanto, consensual que essas mensagens são da ordem da representação sígnica, distinguindo-se do referente que representam. No caso da televisão, são signos icónicos, tal como Peirce os definiu: representam em virtude de uma semelhança, sendo obviamente distintos da coisa significada (ibidem).

Apesar da evidência de ser esta uma representação bidimensional de um corte numa realidade a três dimensões, a não-arbitrariedade do signo icónico torna-o "mais vulnerável" a ser lido como um signo natural, obscurecendo o corte e as operações de encoding/ decoding subjacentes à sua mediatização, especialmente as componentes ideológicodenotativas, que nos signos visuais são pouco evidentes. Em geral, os media codificam a sua mensagem com recurso a códigos conotativos que expressam uma ordem cultural dominante, fornecendo um conjunto de leituras preferenciais, mas não necessariamente unívocas, à audiência (ibidem).

A atribuição conotativa de significados de acordo com a ordem cultural dominante é uma forma de enquadramento das notícias, veículo dispensador de ideologia; mas, como nem sempre o público opera com as categorias do código dominante, podendo por vezes realizar leituras verdadeiramente oposicionais, abre-se espaço, entre a mediatização e a recepção, para uma alteração das concepções culturais dominantes, e um reposicionamento de enquadramentos outrora marginais, defende Hall (ibidem).

Como método de inquirição, a semiótica pode fazer muito pela compreensão dos enquadramentos mediáticos, particularmente no seu flavour peirceano, em que abarca uma ontologia, uma teoria da cognição e uma hermenêutica. Peirce (1977) expressa esta sua concepção omnicompreensiva de semiótica numa célebre passagem de uma carta a Victoria Lady Welby: "... desde o dia em que ... encontrei ... uma cópia da Lógica da Whately ... desde esse dia, nunca mais pude estudar o que quer que fosse-matemática, ética, metafísica, gravitação, termodinâmica, óptica, química, anatomia comparada, astronomia, psicologia, fonética, economia, história da ciência, whist, homens e mulheres, vinho, metrologia - excepto enquanto estudo de semiótica", em que é claro como aspectos da representação, significação, referência e significado pertencem à semiótica, como de

5 Raw event, no original. 
resto decorre da sua célebre definição de signo. ${ }^{6}$ Mas o que é em geral pouco notado é que esta complexidade e abrangência da semiótica decorre da categoriologia - da teoria das categorias peirceanas, que constituem a estrutura de toda a arquitectónica do seu sistema. É esta abrangência e universalidade que permite tomar as categorias peirceanas como princípio e paradigma federador dos estudos de framing. Explicitaremos como adiante.

\section{A terceiridade na génese do habitus interpretativo}

À luz das categorias peirceanas, framing é terceiridade: um hábito interpretativo que se transforma em lei produzindo uma crença sobre o significado e o real (PEIRCE, 1877). Ao partir de uma ontologia e gnosiologia, as categorias peirceanas mostram por que o enquadramento é consubstancial à cognição e expressão humanas (GRADIM, 2006). Tentaremos explicitar essa tese à luz da semiótica peirceana, sem perder de vista que, operando num nível anterior às teorias resenhadas, pode constituir-se como paradigma capaz de as subsumir e organizar, mostrando o que têm em comum todas essas abordagens tão distintas.

Categorias para Aristóteles são os modos como o ser se predica nas coisas, isto é, os predicados que podem ser atribuídos a um sujeito, coincidindo com as grandes divisões do ser; ou seja, terão um alcance simultaneamente linguístico e ontológico - o modo como "dizemos o ser" corresponde ao que o ser é e exaure as suas divisões possíveis".

Kant (1989) termina com essa homologia linguagem-mundo, considerando as categorias determinações do entendimento, formas a priori deste que permitem a constituição dos objetos para o sujeito e a inteligibilidade dos fenómenos. A lista das categorias kantianas elenca os modos de unir sujeito e predicado num juízo, que se identifica com o ato de pensar, mas já não tem incidência ontológica, pois, para o idealismo transcendental kantiano, o ser tal como é permanece incognoscível.

Peirce reformulará as categorias aristotélicas e kantianas numa tríade mais simples, de sabor hegeliano: primeiridade, secundidade, terceiridade. ${ }^{8}$ Ao fazê-lo, "retoma a concepção clássica de categoria como determinação do ser nas suas categorias metafísicas, operando simultaneamente a síntese com o kantismo ao fazê-las coincidir, em lógica e semiótica, com a significação, e, portanto, com a forma do pensamento" (GRADIM, 2006). Para além disso, as categorias peirceanas têm uma pretensão arquitectónica, ou seja, de constituírem as bases de um sistema filosófico capaz de explicar "tudo o que há", e nesse sentido, devem possuir a maior generalidade possível.

6 “Um signo ou representamen é algo que está para alguém a algum respeito ou capacidade. Dirige-se a alguém, isto é, cria na mente dessa pessoa um signo equivalente, ou talvez um signo mais desenvolvido. A esse signo que cria chamo o interpretante do primeiro signo. O signo está por alguma coisa, o seu objecto. Está por esse objecto não em todos os seus aspectos, mas em referência a uma espécie de ideia, que algumas vezes chamei de fundamento do representamen" (Collected Papers, 2.228).

7 A lista das categorias aristotélicas inclui: quantidade, qualidade, relação, lugar, tempo, ação, paixão, estado e posição (Cf. KNEALE e KNEALE, 1980; WARDY, 1998).

8 Firstness, secondness e thirdness, no original. 
A minha perspectiva é que existem três modos de ser. Sustento que podemos observá-los directamente nos elementos do que quer que seja que em dada altura esteja perante a mente de qualquer modo. São eles o ser da possibilidade qualitativa positiva, o ser do facto actual, e o ser da lei que governará os factos no futuro. ${ }^{9}$

Em Para uma nova lista das categorias, Peirce (1868) distingue as três categorias de Qualidade, Relação e Representação, a que depois fará corresponder os ordinais substantivados: Primeiridade, Secundidade, Terceiridade, que se tornaram a imagem de marca da sua categoriologia. Refira-se ainda que é possível abstraí-las por observação fenomenológica como elementos indecomponíveis de todos os fenómenos, mas estas nunca chegam a dar-se de forma pura ou isolada: encontram-se inextricavelmente ligadas no acontecimento.

Primeiridade é caracterizada como "o modo de ser daquilo que é tal como é, positivamente e sem referência a nenhuma outra coisa"(PEIRCE, 1977). Trata-se de uma qualidade primeira, como um som, um cheiro ou uma cor, abstraindo de qualquer suporte e de serem pecepcionados. A cor, por exemplo, não poderia ser percebida sem extensão. É por isso que Primeiridade é uma pura abstração, totalidade potencial, um "absoluto" sem qualquer relação, que existe independentemente de ser percebido ou pensado. "As qualidades são vagas, potenciais e 'imateriais', pois, não entretendo relações com nenhum outro, não reagem nem resistem - serão o primeiro elemento a ter em conta no fenómeno (...). A Qualidade é simples, indecomponível e sem partes, por mais complexo que seja o fenómeno onde inere (...) e é a absoluta ausência de binaridade" (GRADIM, 2006).

Secundidade é o oposto: representa o choque e o confronto, a possibilidade de actualização das qualidades compreendidas na Primeiridade. Estas só podem tomar existência pela concretização numa extensão, o que não se faz sem oposição e resistência. A Secundidade é por natureza binária, e pode ser representada por uma díade. Trata-se de "uma reação enquanto elemento do fenómeno", ${ }^{10}$ da experiência de esforço ou resistência, de uma alteridade que é experimentada como "força bruta", porque alheia a qualquer racionalidade ou fim. Trata-se da "reação cega e bruta que ocorre entre dois primeiros, sem qualquer mediação ou representação" (ibidem) e é essencial à formação da consciência e identidade do sujeito, que se define por aquilo que não é por meio do choque com a alteridade. É a categoria da atualidade e existência, por contraposição com a potencialidade do Primeiro.

Se Secundidade é a pura relação diádica, a Terceiridade é mediação e representação entre os fenómenos: o aparecimento de uma lei ou racionalidade no que é percebido. Uma relação de secundidade é por natureza atual, única; se se repete consistentemente, temos a introdução de uma representação ou lei. Assim, Terceiridade é a categoria que relaciona um Primeiro com um Segundo mediante uma regra ou lei, e envolve sempre

\footnotetext{
9 "My view is that there are three modes of being. I hold that we can directly observe them in elements of whatever is at any time before the mind in any way. They are the being of positive qualitative possibility, the being of actual fact, and the being of law that will govern facts in the future" (Collected Papers, 1.23).

10 Collected Papers, 5.66.
} 
algum tipo de consciência ou acto mental. Torna-se evidente, por exemplo, no signo, onde há uma regra (terceiro) que une um significante a um significado, independentemente do tipo ou forma que essa regra possa assumir, e a que Peirce chamará de fundamento do representamen. Terceiridade compreende então todos os fenómenos cognitivos e mentais que, no caso da interpretação e compreensão do significado, implicam o aparecimento de uma crença.

Simplificando, a semiose, o processo em que algo se torna um signo para alguém, é um processo de descodificação contínua que apenas termina quando o sujeito atinge o estado de "crença": A afinal significa B; sendo que podemos falar de signos individuais, como de longas sequências de texto, situações sociais ou sistemas filosóficos. O processo hermenêutico do sujeito é aberto e culmina na formação de uma crença ou opinião sobre o significado, naturalmente susceptível de revisão e aperfeiçoamento (semiose ilimitada). De resto, este processo de interpretação sígnica no nível do sujeito mimetiza o processo de produção da ciência, que tem por protagonista a comunidade científica como entidade colectiva, e por objecto as leis que regem o universo.

A Terceiridade encontra-se, assim, na génese dos hábitos interpretativos do sujeito, independentemente da extensão ou natureza do objecto interpretado/conhecido. É este o significado do processo de semiose ilimitada, que implica a tradução de qualquer pensamento em pensamentos subsequentes, formando uma cadeia de pensamento, e provocando um diferimento do significado até que o sujeito conclua por um interpretante final ou uma crença, com base na qual desenvolverá a sua ação ou resposta.

\section{Conclusões}

Para uma reinterpretação semiótica do conceito de framing, o trabalho de Peirce sobre as categorias, a sua relação ao funcionamento do signo e a semiose ilimitada oferecem instrumentos poderosos cuja generalidade permite compreender num único paradigma as diversas estirpes da sua origem. A visão sociológica de Goffman, Tuchman ou Bourdieu; a pragmática da comunicação de Bateson; ou o interaccionismo simbólico de Berger e Luckman são diferentes perspectivas do processo de semiose, que extrai regras e procura a racionalidade subjacente aos fenómenos que observa, enquadrando-os num processo interpretativo que é sempre provisório e revisível, isto é, evolutivo.

A esta luz, a introdução da semiótica como método de desocultamento e paradigma interpretativo na genealogia do framing é um dispositivo de análise poderoso que pode marcar novas metodologias na codificação e análise das teorias de enquadramento, fornecendo o embasamento epistemológico destas. No nível das aplicações e dos estudos empíricos, em que esta dispersão metodológica se torna muitas vezes sensível, a perspectiva triádica peirceana poderia reforçar epistemologicamente as metodologias empregadas, assegurando que as frames não são meras construções do sujeito (nominalismo), mas pertencem ao objecto estudado (realismo), algo absolutamente necessário para que tais estudos demonstrem conseguir escapar às armadilhas da ideologia. 
A semiótica aparece então aqui como elemento criador da produção de sentido em contexto, que é precisamente o objecto, tão elusivo, que as teorias de framing procuram apontar. As categorias peirceanas, ao identificarem o sentido com a terceiridade e os hábitos interpretativos do sujeito chegam à raiz psicolinguística do enquadramento, mostrando e desdramatizando a sua inescapabilidade - não é possível conhecer sem enquadrar - ao mesmo tempo que dão os instrumentos para ver com transparência o fenómeno: enquadramento sempre está lá: no produtor, no objecto, e no sujeito. Frame é um processo dinâmico entre três pólos: o produtor, os conteúdos mediáticos, as audiências. Da interação entre esses três níveis de semiose nascerá a política e a deliberação; a opinião pública, a manipulação e o esclarecimento.

Muito mais estudos, não só teóricos, mas, sobretudo, empíricos, serão necessários para mostrar que o enquadramento, passe o oxímoro, só é transparente quando se torna visível; e que é nesse campo hoje, nas sociedades da mediatização globalizada, que se joga o esclarecimento (aufklärung) e, consequentemente, a possibilidade de emancipação democrática. A semiótica é uma disciplina fundamental para essa construção.

Anabela Gradim é licenciada em Filosofia pela Universidade do Porto e doutorou-se em Ciências da Comunicação na Universidade da Beira Interior. É diretora do programa de doutorado em Ciências da Comunicação da UBI e investigadora do Labcom - Laboratório de Comunicação Online. Seus interesses de investigação prendem-se com o Jornalismo, a Comunicação de Ciência, a Semiótica, a Retórica e a interface dessas disciplinas com a Cibercultura e os Novos Media.

anabela.gradim@labcom.ubi.pt

\section{Referências}

BATESON, G. Steps to an ecology of mind: collected essays in anthropology, psychiatry, evolution, and epistemology. Chicago: University of Chicago Press, 1972.

BERGER, P. L.; LUCKMANN, T. A construção social da realidade: tratado de sociologia do conhecimento. Petrópolis: Editora Vozes, 1974.

BIRD, E.; DARDENNE, R. Rethinking news and myth as storytelling. In: WAHL-JOERGENSEN, K. e HANITZSCH, T. (Ed.). The handbook of journalism studies. New York: Taylor \& Francis, Routledge, 2009. (ICA Handbook Series).

BIRKLAND, T. A.; LAWRENCE, R. G. Media framing and policy change after Columbine. American Behavioral Scientist, v. 52, n. 10, pp. 1405-1425, 2009.

BOURDIEU, P. Sobre a televisão. Oeiras: Celta Editora, 1997.

ENTMAN, R. Framing US coverage of international news: contrast in narratives of the Korean and Iranian Airline incidents. Journal of Communication, v. 51, n. 4, p. 6-27, 1991. 
ENTMAN, R. M. Framing: Toward clarification of a fractured paradigm. Journal of communication, v. 43, n. 4, p. 51-58, 1993.

Media framing biases and political power: explaining slant in news of Campaign 2008. Journalism, v. 11, n. 4, p. 389-408, 2010.

GAMSON, W. A.; MODIGLIANI, A. Media discourse and public opinion on nuclear power: a constructionist approach. American journal of sociology, p. 1-37, 1989.

GITLIN, T. The whole world is watching: Mass media in the making \& unmaking of the new left. University of California Press, 1980.

GOFFMAN, E. Frame analysis: an essay on the organization of experience. Harvard University Press, 1974.

. A apresentação do eu na vida de todos os dias. Trad. Miguel Serras Pereira. Lisboa: Relógio d'Água, 1993.

GRADIM, A. Comunicação e Ética. O sistema semiótico de Charles S. Peirce. Covilhã: Labcom Books, 2006.

HALL, S. Encoding/decoding. In: DURING, S. (Ed.). The Cultural Studies Reader. London and New York: Routledge, 1999. cap. 36, p. 507-517.

JOHNSON-CARTEE, K. S. News narratives and news framing: constructing political reality. New York: Rowman \& Littlefield Publishers, 2004.

KANT, I. Crítica da Razão Pura. Lisboa: Fundação Calouste Gulbenkian, 1989.

KAREN, C.; FRAUKE SCHNELL, E. Framing American Politics. Pittsburgh: University of Pittsburgh Press, 2005.

KNEALE, W.; KNEALE, M. O desenvolvimento da lógica. Lisboa: Fundação Calouste Gulbenkian, 1980.

LAKOFF, G. Don't Think of an Elephant! Know Your Values and Frame the Debate: the Essential Guide for Progressives. Vermont: Chelsea Green Publishing Company, 2004.

NORRIS, P.; KERN, M.; JUST, M. R. Framing terrorism: the news media, the government, and the public. New York \& London: Routledge, 2003.

PEIRCE, C. S. Sobre uma nova lista de categorias. In: Proceedings of the american academy of arts and sciences. 7: 287-298, p. 1868.

. A fixação da crença. In: Popular sci. Monthly 12, 1877.

Semiotic and significs: the correspondence between Charles S. Peirce and Victoria Lady Welby. Indiana University Press, 1977.

REESE, S. D.; GANDY JR, O. H.; GRANT, A. E. Framing public life: perspectives on media and our understanding of the social world. Routledge, 2001.

TUCHMAN, G. Making news: a study in the construction of reality. New York: Free Press - Simon \& Schuster, 1980.

WARDY, R. Categories. In: Routledge Encyclopedia of Philosophy. CRAIG, E. London, Routledge, 1998. p. 229-233. 